look upon this circumstance with the most implicit confidence as the sign that sawing wood is what he was intended for. S. L. Clemens (Mark Twain): A General Reply, 1870.

\section{Acknowledgements}

I am grateful to Professor Hugh Freeman and Ralph Footring, scientific editor, for their help, and to H. L. Mencken's (1984) Dictionary of Quotations, published by Collins, London.

\section{Further reading}

Lock, S. (1977) Thorne's Better Medical Writing. Tunbridge Wells: Pitman.

O'CONNOR, M. \& WOODFORD, F. P. (1975) Writing Scientific Papers in English. Amsterdam: Associated Scientific Publishers.

Paton, A. (1985) Write a paper. In How To Do It (Second edition). London: BMA.

PrINS, H. (1989) Getting your papers published: or how to win editors and influence assessors. Psychiatric Bulletin, 13, 14-15.

\title{
The nuts and bolts of writing papers
}

\section{Number 4: Technical matters}

\author{
RALPH FoOtRING, Scientific Editor, British Journal of Psychiatry
}

\section{Jargon}

Some jargon is useful. Though I invariably place inverted commas around 'caseness', just so that everybody knows that I know that it is jargon, I would be a lost man if I diligently replaced it with a statement to the effect that this particular patient has achieved an index of definition of 5 or over on the Present State Examination.

I would like to make a special plea here for the use of the word 'case'. Popular dictionaries do indicate it can be used to refer to people, but I really do think it's a bit much, inhumane even, to refer to six cases having children. Butterworths' Medical Dictionary gives "Any particular instance of injury or disease". I have even read of cases coming to post mortems. Some papers are full of cases that I have to assiduously amend, which can take a lot of patients.

Interestingly, Butterworths' Medical Dictionary gives two definitions of 'jargon', the first of which, topically perhaps, is "The babbling talk and incomprehensible words uttered by certain idiots and by insane persons".

Some jargon is used by cunning authors to add a dubious authority to their writing. The worst case I have yet come across of this was 'positive futureorientated mental construct', which really sounded great in context, but 'hope' was actually more honest.

\section{Patient numbers}

If the reports I read are to be believed (and one can only assume that they are), anyone entering a hospital (or perhaps it is only a research study) is endowed with the ability to disappear. This is doubly true if he or she is also a percentage. Fifty per cent of the last 30 papers to pass my desk contained numerical errors - three had over three errors, ten had only one.

There is also the sort of patient who can materialise out of nothing at all. They generally do it in tables, but wily ones work themselves into a footnote.

\section{Practical advice}

I would suggest thinking how a technical something could be said in plain English - if it is shorter the plain way, say it that way; if it is longer, there is still the consideration of your audience, and whether they will readily understand.

The other point about technical matters is that they are very easily overlooked or forgotten, even by authors. You should therefore make sure that what you've said in one place tallies with what you've said somewhere else. Cross-checking facts within the paper itself can show up the trivial reference error as well as the more than somewhat embarrassing numerical howler. 